UDC 159.922.7

Ruben MIRZAKHANYAN,

Srbuhi GEVORGYAN,

Vladimir KARAPETYAN,

Alla DALLAKYAN,

Asya BERBERYAN

\title{
TYPICAL EXPRESSION OF COGNITIVE DISSONANCE AND CONSONANCE IN THE COURSE OF ARGUMENTATION AMONG PRIMARY-SCHOOL CHILDREN PLAYING CHESS
}

\begin{abstract}
The research aims to reveal the typical expressions of cognitive dissonance and consonance among the primary-school children by their argumentations upon their deed. The relevance of the research stems from the applicability of the study of the phenomena of dissonance and consonance, which inherently emerge in the sphere of argumentation among the children who study how to play chess. Cognitive dissonance and consonance in the sphere of argumentation in the course of the game of chess are gradually transforming both into the respective reference points - relevant to the situation given, and into the emotional and behavioural manifestations - either adequately or inadequately expressed and, by the logical and inner conflict, are observed as the result of juxtaposition of the realms of emotions and logic.

The present research evidences that, in the case of similar chess skills, the manifestation of cognitive dissonance, and the own argumentation as well are detectable within the domain of extroversion - emotional instability. Such children, even more than the introverts, need the school psychologist's support. The cognitive consonance is typical of those of the children involved who are ready to gain new experience and appear to be more positively charged towards their rivals or opponents.
\end{abstract}

Keywords: cognitive consonance, cognitive dissonance, psychometric personality tests, personality dimension tests, chess, children, chess teachers, school psychologists.

Introduction and Literature Review

The notion of cognitive dissonance, set forth by Leon Festinger in 1956, played it significant role both in the development of cognitive psychology and in the uncovering the peculiarities of psychological and subjective argumentation.

Cognitive dissonance, as a complex psy chological state, finds its ways of expression in the human consciousness through the collision of several judgments, comments, and, though concrete - however, incompatible within the given process of argumentation - conceptions or visions of the same phenomenon, fact or deed. According to Festinger (1957), cognitive dissonance is defined as an incongruity among many, mutually exclusive cognitions - deeds, 
acts, judgments, and facts. In case one of the cognitions mentioned above is ignored, the subject faces a discomfort since the consciousness marks some contradictory and incompatible "pieces" of knowledge about the same phenomenon, event or object. The theory of cognitive dissonance determines the ways of halting or mitigation of the contradictions as mentioned earlier, as well as, and it pictures how humans, on average, typically cope with. L. Festinger (1957) claims that cognitive dissonance, in personality' consciousness, is a psychological phenomenon which must necessarily be observed as a result of mutually exclusive conceptions, opinions and notions of two or more objects involved in the same activity or subject matter, which with their discrepancy, as a severe potential reason for "collision" while in search of further steps or as an obstacle for further inferences or conclusions, influence not only the adequate orientations but also people's emotional and behavioural manifestations. The issues mentioned earlier have not been sufficiently explored from the perspective of argumentation aimed at confirming or denying facts, phenomena or deeds (Festinger, 1957). The logic-based contrast and the conflict-entailing contradiction might distort essential facts, thus, impeding any further grounding of argumentations, and, naturally, resulting in difficulties related to the search for pieces of evidence while trying to explain others one's deeds.

From the standpoint of psychological analysis, the manifestations of cognitive dissonance and consonance appear to be complicated, contradictory, sometimes, without the necessary evidence as the respective premises, preconditions, personal interests and social settings in the course of argumentation, the concrete condi tions and the variety of factors, which require the necessary logical coherence, are not always compatible for an objective and comprehensive analysis, especially, in condition of simultaneous application of the respective standards accepted within experimental Psychology and Logic (Karapetyan, 2012; Karapetyan, Gevorkyan, \& Petrosyan 2014; Karapetyan, 2016). Quite aware of the depth of these issues in the sphere of argumentation, we find it convenient to separate some contradictions of psychological character the manifestation of which more explicitly help to detect the presence or absence of dissonance or consonance in concrete situations and conditions. More precisely speaking:

- the contradictions between the broadening of person's judgments and opposing either concrete or general judgments within the whole process of providing any reality with the own evidence (Nepryakhin, 2010; Carnap, 1936),

- the contradiction between the presence of purely subjective personal judgments within the context given - reckoned by the person as logical and substantiated, on the one hand, and self-guidance through the socalled pseudo-judgments which do not correspond to the context given, especially, in the cases when the person tries to conceal the reality connected with some conditions or situations,

- the contradiction between the given series of judgments or statements and its application or applicability beyond the context given - on sensuous cognition level (for instance, when the interlocutor say, "You cannot understand as you were not there, and, besides, you have not seen what I 


$$
\text { saw..."). }
$$

\section{Method}

The sphere of judgments is intruded by the given person's sensuous information - related to the person's visual, audio or kinetic sensations and not always objectively and unambiguously detectable. In this case, the dissonance occurs providing, while conversing, the interlocutors mainly make use of their methods of processing information, categorically rejecting the information through all other sensory channels.

The combination of the sensory and logical within the sphere of argumentation, as a rule, on the personal level, emerges through a mechanistic synthesis of the concrete and abstract which makes any further quotation or use of argumentation insensible. The question then arises on why some people relate the verbal means of expression of dissonance and consonance, mainly, to the sensory cognition of their observations. This might be explained not only with the help of emotional safety or protection, the necessity of immediate connections with the matter, tangible or real-world but also with the rational thinking and the logic of their judgments. At all events, the problem is confined to the correspondence of a person's real aim and motivation to the activation of any component typical of argumentation. In the course of a conversation, the motivation of entering the semantic realm at verbal level (namely, what is allowed and what is not allowed, i.e. banned), from time to time, makes the person project herself/himself in the matter-based world for the sake of target-oriented perception and analysis of sensory information. The question that derives is as follows: how does a personality, due to her/his characteristics, actually combine the sensory and the logical or the constituents of the sensory and logical infrastructures in the course of argumentation?
The core, guiding method in the research was the inductive research analysis based on the results and aimed at detecting the typicality in the ways cognitive dissonance and consonance are expressed within the process of argumentation with the respective age group of children involved and from the perspectives of the relevance of the moves that they chose while playing chess.

During the target-oriented talks conducted with randomly chosen two chess player out of the group of schoolchildren from the $2^{\text {nd }}$ to the $4^{\text {th }}$ grades of primary school, as well as with the chess teacher and school psychologist with the necessary skills of playing chess, the respective records were kept to file the explanation of the moves, their logical basis and relevance, the respective emotional overtones marked, the feelings and senses among the school children playing chess. The chess teacher was persistently finding out the reasonability of the moves following the argumentation-based logic behind the given games.

The psychologist was there to detect the emotionality and behavioural patterns among the children involved in the game. Moreover, at the end of every game, the psychologist's mission was to comfort the children who had lost the game with the help of several professional consultancies.

The application of Eysenck's personality psychometric test was meant to record the respective average data collected in the course of detecting the individual psychological qualities of school children's personalities in two directions: "Emotional stability - Neuroticism (Emotional instability)" and "Extroversion - Introversion" for their further comparison with the ex- 
pression of cognitive dissonance and consonance among the children in general - within the school class or group (Eysenck \& Wilson, 2000).

The "Big 5" test (Goldberg, 1990), designed for psychometric personality qualities, was used to detect the degree of readiness (openness versus reticence) for gaining new experience. In practice, any personality tries to find the respective strategy of the logic of activities within the intra-psychological world likening them with intermediate achievements or the results of individual experience - without the sufficient level of systematisation and generalisation - with apparent preference granted to the knowledge and opportunities gained in the matter-based world as a result of personal experience or as a means of testing anything. The automatic synthesis of the sensory and the logical leads to some logical mistakes. For instance, while proving a mathematical theorem, a student says, "We can see that the given line is longer; therefore, we have no actual problem to prove". The teacher replies that the case given is concrete; however, it is needed to prove precisely that, ir- respective of the position occupied, the segment of the line given is always longer. As a matter of fact, it turns out that judgments, based mainly on the sensory information within the sphere of argumentation, are more likely to lead to logical mistakes, consequently, after the synthesis of the sensory and the logic, the phenomenon of dissonance finds a more vivid expression. The activity of the sensory component appears to be dominant when the complete scheme of information processing is based on visual, audio and kinetic skills without further penetration into the depths of the logical component of argumentation. The question that arises is whether dissonance might be conditioned by personality qualities, in particular, by the activity of the neural system.

Let us observe two of the general psychometric methods of personality qualities connected with argumentation: (1) Eysenck's personality test (Eysenck \& Wilson, 1976) and (2) the "Big Five" (Goldberg, 1990).

See Diagram 1 for the two dimensions of personality according to Eysenck.

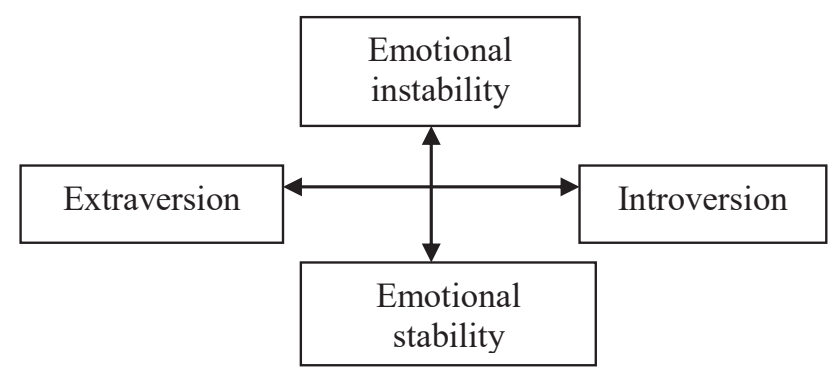

Diagram 1. Personality dimensions according to Eysenck (Eysenck \& Wilson, 1976)

In the preliminary experiment stage, we revealed that the phenomenon of dissonance more frequently emerges within the quality characteristics "Extroversion -Emotional instability [Sector 1] and "Emotional stability - Introversion" [Sector 2]. Thus, from the psychological peculi- arities of a choleric and a melancholic, we might draw a preliminary conclusion that the phenomenon of dissonance in argumentation occurs more frequently among the above-mentioned psychological types. At the same time, having studied the big five - (1) "Extroversion - Intro- 
version", (2) "Neuroticism - Emotional stability", (3) "Openness versus reticence towards a new experience", (4) "Consciousness - distraction", (5) "Friendliness - Animosity" (Goldberg, 1990) it becomes clear that the phenomenon of dissonance appears to be more vividly expressed within the domain of personal qualities of "Extroversion - Introversion" and "Neuroticism Emotional stability". Meanwhile, (3) "Openness versus reticence towards a new experience", (4) "Consciousness - distraction", (5) "Friendliness Animosity" are particularly typical in the conditions of cognitive consonance when the personality tends to reach solidarity based on the cooperation principles. Therefore - he/she is ready to listen to other party's argumentation and more likely to express tolerance.

In order to prove the present judgment, the following three situational conditions were analysed:

1) The concrete situations when the personal ways of expression and behaviour were motivated by the argument "for" and "against" at the same time (in practice, not all people can manifest the necessary reflective skills for the analysis of their deeds).

2) The situations when the choice of strategy of rationalising one's judgments, opinions, conceptions would derive from the same person's motivations, aims, and logical acts.

3) The situations when the combination of aims and deeds not only seems to be real within the series of judgments but also quite feasible as figured out by the person himself/herself.

For empirical research objectives, the primary school child playing chess was chosen as a respondent. Three research groups were formed upon the basis of qualitative data - 10 pairs of children in each. Inside every group of respond- ents, there were different subgroups formed with different variations. The chess instructor of the given group, as well as, the psychologist of the school or the given educational institution also took part in the experiment.

The game was monitored by the instructor (chess teacher) and school psychologist. At every move, the teacher would ask the child about the relevance of the move without interfering or reminding about the adequacy of the given move. The game partner would always hear the questions asked. The psychologist's mission was, while following the whole game process, to organise private consultancy for every child afterwards, in order to keep the children away from depression - possibly caused by the loss or excessive excitement - in case of a win. The psychologist was trying to teach to lose honestly and somewhat considering that loss as a mere experience in playing chess. The valid argumentation was highlighted as a significance instance. The personal qualities of the children involved were also measured by Eysenck's (Eysenck \& Wilson, 1976) and "Big 5" (Goldberg, 1990) tests.

\section{Results}

In every school class, comprising children from the $2^{\text {nd }}$ to the $4^{\text {th }}$ grades, only those randomly chosen children's moves were singled out and researched which would result in the phenomena of dissonance and consonance both during and after the game. The table below contains the average data on the chess moves of one child reckoning the instances of expression of personal qualities within the following dimensions "Emotional stability - Neuroticism", and "Extraversion - Introversion". The child's moves, made in the chess teacher's presence, were chosen as units of measurement of argumentation. 
Since the phenomena of cognitive dissonance and consonance were expressed among the children after a certain number of moves, the aver- age number of moves of every child during the games may vary (see Table 1).

Table 1 .

The Expression of Personality Qualities According to the Moves.

\begin{tabular}{|c|c|c|c|c|c|c|c|}
\hline 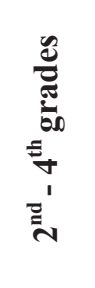 & 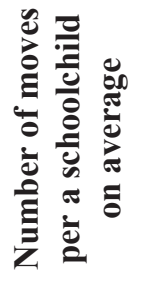 & 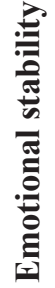 & 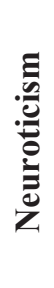 & 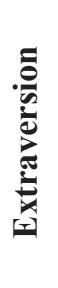 & 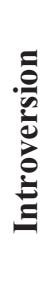 & 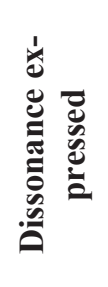 & 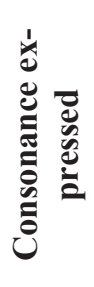 \\
\hline $\begin{array}{l}2^{\text {nd }} \\
\text { grade }\end{array}$ & 10 & $\frac{\bar{d}}{\stackrel{\vec{d}}{]}}$ & $\frac{\overrightarrow{0}}{\stackrel{0}{0}}$ & & + & - & + \\
\hline $\begin{array}{l}3^{\text {rd }} \\
\text { grade }\end{array}$ & 18 & 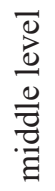 & $\begin{array}{l}\overline{0} \\
\frac{0}{0} \\
\text { zo }\end{array}$ & - & + & - & + \\
\hline $\begin{array}{l}4^{\text {th }} \\
\text { grade }\end{array}$ & 28 & $\frac{\overline{0}}{\frac{0}{0}}$ & $\begin{array}{l}\overrightarrow{0} \\
\overrightarrow{0} \\
\overrightarrow{000} \\
.0\end{array}$ & + & - & + & - \\
\hline
\end{tabular}

The phenomenon of dissonance detected among the $4^{\text {th }}$-grade schoolchildren appeared to be connected with logical mistakes or absence of alternative solutions for the given game. However, they proved to be more extroverts, sociable and open in the course of gaining a particular experience, which becomes evident while analysing the details of the games. As for the schoolchildren of the $2^{\text {nd }}$ to the $3^{\text {rd }}$ grades, they appeared to manifest the phenomenon of consonance: they would attentively listen to the analyses and would accept the results of the game and the logical mistakes and arguments in peaceful disposition and without conflicts. The results of the interview conducted by PARLA method ${ }^{1}$, as well as the analysis of chess video game have revealed that the efficiency of the move assimilated does not necessarily correspond to its use in the future.

PARLA method was also applied in the course of argumentation with the following objectives:

a) the respective combination or correlation of the chess instructor's and psychologist's data with the results acquired through PARLA method.

b) the continuous and scrupulous observation of the game of chess within the respective

1 See http://www.hr-journal.ru/articles/pp/STARIntervju-po-kompetencijam.html () HR-Journal.ru. 
"problem - move (action/deed) - result learning - application."

c) the uncovering of the personal qualities of a chess player that are manifested, in particular, within the learning-application cycle.

The study also explored how school children learned how to argue on their moves and how to apply them. As it has turned out, that the application of PARLA method is more relevant after the joint work of the chess instructor and psychologist as, within these joint efforts, the number of new actions (moves), that are entirely new to the schoolchild, increases (learning and application). The table below comprises the results of the ten playing pairs - irrespective of the results of the games for the opponents.

The Results Based on Components PARLA, see Table 2.

Table 2.

The Results Based on Components PARLA

\begin{tabular}{|c|c|c|c|c|}
\hline $\begin{array}{l}\text { Conventional partici- } \\
\text { pants' identification } \\
\text { numbers defined for } \\
\text { the playing pairs }\end{array}$ & $\begin{array}{l}\text { Number of } \\
\text { moves } \\
\text { (actions) }\end{array}$ & $\begin{array}{l}\text { Actions results ac- } \\
\text { cording to the sig- } \\
\text { nificance of the } \\
\text { moves }\end{array}$ & $\begin{array}{l}\text { Learning by the } \\
\text { erroneous } \\
\text { moves }\end{array}$ & Action applied \\
\hline 1 & 12 & 8 & 6 & 4 \\
\hline 2 & 10 & 9 & 7 & 5 \\
\hline 3 & 8 & 7 & 5 & 3 \\
\hline 4 & 11 & 10 & 8 & 6 \\
\hline 5 & 13 & 12 & 3 & 7 \\
\hline 6 & 7 & 6 & 4 & 4 \\
\hline 7 & 9 & 8 & 6 & 5 \\
\hline 8 & 14 & 13 & 3 & 2 \\
\hline 9 & 16 & 15 & 8 & 11 \\
\hline 10 & 5 & 4 & 1 & 2 \\
\hline 11 & 12 & 11 & 4 & 4 \\
\hline 12 & 10 & 9 & 6 & 7 \\
\hline 13 & 8 & 7 & 5 & 6 \\
\hline 14 & 11 & 6 & 8 & 5 \\
\hline 15 & 13 & 7 & 6 & 7 \\
\hline 16 & 7 & 5 & 3 & 3 \\
\hline 17 & 9 & 8 & 4 & 6 \\
\hline 18 & 14 & 9 & 5 & 10 \\
\hline 19 & 16 & 11 & 7 & 9 \\
\hline 20 & 5 & 4 & 2 & 3 \\
\hline
\end{tabular}

The first column contains the conventional identification number of players, and the second column shows the number of moves per player. The scores in the third column show the move that was particularly significant for the given player. The fourth column presents the figures connected with the wrong moves in the learning process. The fifth column comprises the moves that will be applied by the player in the future.

The correlational analysis of the indicators in columns 2-5 is introduced in Table 3 below. 
Correlational Coefficients of the Results Gained

Through the Characteristic Indicators of PARLA Method

\begin{tabular}{|c|c|c|}
\hline $\begin{array}{c}\text { Correlational dependence among the } \\
\text { main components }\end{array}$ & $\begin{array}{c}\text { Correlational } \\
\text { coefficients }\end{array}$ & Definition formulas \\
\hline $\begin{array}{l}\text { The correlation between the number of } \\
\text { actual moves and choice of the moves } \\
\text { of particular significance for the player } \\
\text { (columns } 2 \text { and } 3 \text { ) }\end{array}$ & 0.8398 & $\mathbf{P x y}=\frac{\operatorname{Cov}(X, Y)}{ð x \partial y}$ \\
\hline $\begin{array}{l}\text { The correlation between the number of } \\
\text { actual moves and the awareness of erro- } \\
\text { neous moves (columns } 2 \text { and } 4 \text { ) }\end{array}$ & 0.3569 & $\operatorname{Corel}(X, Y)=\frac{\sum(X-x)(Y-y)}{\sqrt{\sum(X-x) 2(Y-y) 2}}$ \\
\hline $\begin{array}{l}\text { The correlation between the number of } \\
\text { actual moves and the choice of the } \\
\text { moves learnt (columns } 2 \text { and } 5 \text { ) }\end{array}$ & 0.5742 & $\operatorname{Corel}(X, Y)=\frac{\sum(X-x)(Y-y)}{n}$ \\
\hline $\begin{array}{l}\text { The correlation between the moves of } \\
\text { utter significance for the player and the } \\
\text { awareness of the erroneous move (col- } \\
\text { umns } 3 \text { and 4) }\end{array}$ & 0.3839 & $\operatorname{Corel}(X, Y)=\frac{\sum(X-x)(Y-y)}{\sqrt{\sum(X-x) 2(Y-y) 2}}$ \\
\hline $\begin{array}{l}\text { The correlation between the moves of } \\
\text { particular significance for the player and } \\
\text { the moves learnt (columns } 3 \text { and 5) }\end{array}$ & 0.541 & $\operatorname{Corel}(X, Y)=\frac{\sum(X-x)(Y-y)}{\sqrt{\sum(X-x) 2(Y-y) 2}}$ \\
\hline $\begin{array}{l}\text { The correlation between the awareness } \\
\text { of the erroneous moves and the choice } \\
\text { of the moves learnt (columns } 4 \text { and 5) }\end{array}$ & 0.5787 & $\operatorname{Corel}(X, Y)=\frac{\sum(X-x)(Y-y)}{\sqrt{\Sigma(X-x) 2(Y-y) 2}}$ \\
\hline
\end{tabular}

The indicators of the correlational analysis evidence that the schoolchildren playing chess get oriented mainly in the case of the choice of the most significant move - irrespective of the duration of studies: this is grounded by the high indicator of correlational coefficient between columns 2 and 3 (0.8398). We may consider, as a sound indicator, the correlation between the awareness of the wrong move and the choice of the move learnt in the course of the game, as well $\left(0.5787\right.$ - between the $4^{\text {th }}$ and 5 the columns). Nevertheless, we can observe a rather low-degree correlational dependence between the move of particular significance for players and awareness of the wrong move $(0.3839$ - col- umns 3 and 4), which, in the course of argumentation, does not contain cognitive consonance allowing to be aware of the errors in the moves made. The course of research shows that the phenomenon of cognitive dissonance is observed among emotionally unstable children: they do not take into consideration the mistakes of previous moves and make use of it again. The cognitive dissonance among the emotionally unstable schoolchildren also finds manifestation at learning stage: they appear to be reluctant in correcting their own mistakes; meanwhile, the emotionally stable schoolchildren appear to be more open to communication and ready to accept their own mistakes. The introvert children, while 
looking for ways to correct their mistakes, tend not to ask for help from the chess instructor or of the school psychologist. Whereas, the extraverts - open to socialising after every game - irrespective of the results - appear to be interested in the adequacy of their moves, thus, they are disposed to correct their own mistakes with the help of the chess instructor or the school psychologist. Such disposition might be viewed as the result of learning or actual use. Thus, the expression of cognitive consonance is typical of the schoolchildren who are ready to gain new experience and are positively disposed towards the game partner/opponent.

\section{Conclusion}

The psychological analysis of the primaryschool children playing chess detected cognitive dissonance and consonance within the explicit expression of dominant individual psychological qualities of personality. The researches outlined above evidence that, in the case of comparable chess lessons and skills, the manifestation of cognitive dissonance, together with argumentation, respectively, is detectable within the domain of "Extroversion - Emotional instability" which entails that the respective group of children needs more support from the school psychologist. Cognitive consonance is a characteristic of the children who appear more disposed towards gaining new experience and are more positively charged towards their game opponent. The logic of the Big 5 test (Goldberg, 1990) also leads to the conclusion that cognitive dissonance is more often expressed in players' behaviour among the players with animosity expressed towards the game partner sitting in front of them.

Observed from the psychological perspectives, we can state some difference in social roles. The high-rank chess player tends to defend their positions during the game more confidently: thus, cognitive consonance among them is manifested in the course of logical analysis of the grounding shreds of evidence of the actions they take on the chessboard.

Therefore, the results of the experiments, conducted within this research, evidence that, as a matter of fact, in case of comparable knowledge and skills in chess, the schoolchild's respective dissonance and argumentation find their direct manifestation within the domain "Extraversion - Emotional instability", and these schoolchildren appear to need the school psychologist's support more than the respective group of introverts. The phenomenon of consonance is evident in those schoolchildren who require gaining new experience in the course of the game; therefore, they appear to be more positively disposed towards the game partner/opponent. From the standpoint of the Big 5, the phenomenon of dissonance emerges in the behaviour of the schoolchildren charged with animosity towards the peer player. From the psychological perspective, it would also be interesting to explore the difference in social roles detected. All again, the players of higher qualification in chess appear to defend their position, their combinations more confidently during the whole game, which in fact, is the phenomenon of consonance evidenced through the logical analysis of the evidence basis of their actions.

\section{REFERENCES}

Carnap, R. (1936). Testability and Meaning. Philosophy of Science, 3(4), 419-471.

Goldberg, L. (1990). An Alternative «Description of Personality»: The Big-Five Factor Structure. Journal of Personali- 
ty and Social Psychology, 59(6), 12161229.

Eysenck, H. J., \& Wilson, G. D. (1976). Know your Own Personality. Penguin Books.

Eysenck, H. J., \& Wilson, G. D. (2000). Kak izmenit' lichnost' (How to Change a Personality, in Russian) (A. Belopolski, Trans.). Moscow: OOO "KogitoTsentr".

Festinger, L. (1957). A Theory of Cognitive Dissonance. Stanford University Press.

Karapetyan, V. S. (2012). Self-Development of Transforming Society as a Process of Identification of New Paradigm. News and Views, 4(2-3), 154-158.

Karapetyan, V., Gevorkyan, S., \& Petrosyan, R. (2014). Target-Oriented Research of the Strategic Programmes on Chess
Activities as Specialised Experimental Platform for Dynamic Development of Public Education. In Proceedings of the International Conference "Chess in Schools” (pp. 41-49). Yerevan, Armenia.

Karapetyan, V. S. (2016). Research as a Deliberate Chess Software Testing Platform for Professional Dynamic Development of the Education Sector. Management Studies, USA, 4(4), July-August, 161-167.

Nepryakhin, N. Yu. (2010). Ubezhdai i pobezhdai. Sekrety effektivnoi argumentatsii (Convince and Conquer. Secrets of Effective Reasoning, in Russian). Mocow: Alpina Publisher. 